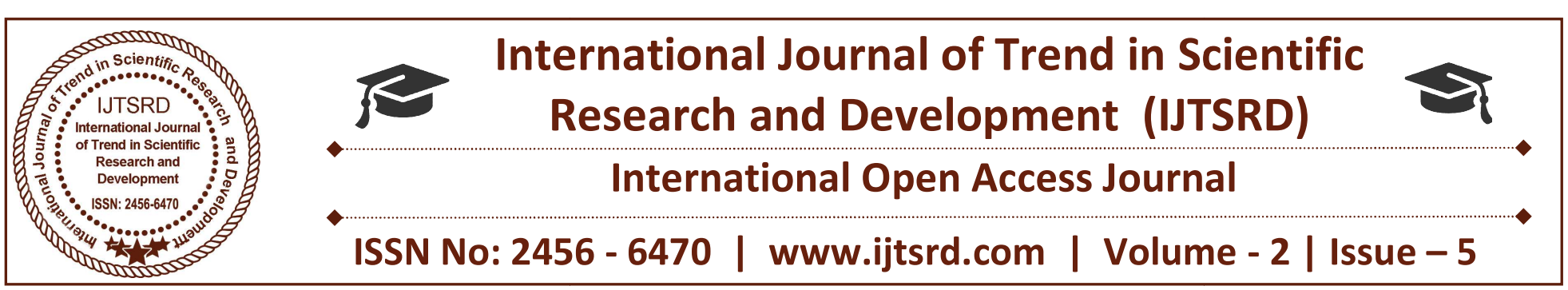

\title{
Benchmarking and Employee Job Satisfaction in Adamawa State University, Mubi
}

\author{
Dr. Sanusi Bello \\ Department of Business Administration, Adamawa State University, \\ Mubi, Adamawa State, Nigeria
}

\section{ABSTRACT}

Benchmarking is now a commonplace term in business and many definitions have been proposed. Despite its increasing popularity there is growing evidence that it is often used incorrectly. 'Benchmarking' seems to be confused with competitive comparison studies, which are simply a component part of benchmarking. This work reviews previous benchmarking studies in general, identifying the background to its growth, and benefits and barriers relating spec to implementation by Adamawa State University, Mubi. A key to accomplishing this goal is by benchmarking their performance against other institution. Benchmarking can be expensive, time consuming, or problematic because detailed benchmarking requires detailed, specific data that are generally confidential. A screening level benchmark can accomplish much of the goal quickly and cheaply. Therefore, the main objective of this study is to assess if benchmarking has an effect on employees job satisfaction in Adamawa State University, Mubi. A descriptive research design with survey method was applied in this study. The study used both the primary and the secondary data for the purpose of this study and a sample of 262 staff was obtained through Taro Yamani formula. The study found out that there is a significant effect of benchmarking on employees job satisfaction in Adamawa State University, Mubi. In lieu of this, the study recommended that adequate benchmarking technique should be adopted such that standard of the school can be improved as well as enhancing adequate employees job satisfaction.

Keywords: Benchmarking, Employees, Job Performance.

\section{INTRODUCTION}

Nowadays many firms like to concentrate on gaining a competitive advantage in the market. The advance equipments, new technology, good marketing strategy, excellent customer services and many other elements can be the factors to build up for the advantages. However, employees are the most important assets of an organization and its success or failure depends on their qualifications and performance which can be achieved when they are satisfied with their job. The employees are the repository of knowledge, skills and abilities that can't be imitated by the competitors. Technologies, products and processes are easily imitated by the competitors; at the end of the day, employees are the most strategic resource the organization (Elnaga and Imran, 2014).

A new way of management which can aid in the pursuit of the organizational strategy is benchmarking. Benchmarking is the process of improving perforihance by continuously identifying, understanding, and adapting outstanding practices and processes found inside and outside an organization (company, public organization, University, College, etc.) (Kelessidis, 2000).

Benchmarking according to Kelessidis (2000) was pioneered by Xerox Corporation in the 1979s, as part of their response to international competition in the photocopier market, and originated from reverse engineering of competitors' products. Its scope was then enlarged to include business services and processes. Xerox now benchmarks nearly 240 performance elements although, when' they started benchmarking several years ago; considerably fewer elements were benchmarked (ibid). 
Benchmarking of business processes is usually done with top performing companies in other industry sectors. This is feasible because many business processes are essentially the same from sector to sector. Benchmarking focuses on the improvement of any given business process by exploiting "best practices rather than merely measuring the best performance. Best practices are the cause of best performance. Organizations studying best practices have the greatest opportunity for gaining a strategic, operational, and financial advantage (Ajelabi and Tang, 2010).

Benchmarking should be looked upon as a tool for improvement within a wider scope of customer focused improvement activities and should be driven by customer and internal organization needs. Benchmarking is the practice of being humble enough to admit that someone else is better at something and wise enough to learn how to match and even surpass them at it.

Benchmarking became popular several decades ago as part of the total quality management movement (Kaplan, 2005). Kaplan (2005) went on to perceive benchmarking as the ongoing activity of comparing one's own process, product, or service against the best-known similar activity, so that challenging but attainable goals can be set and a realistic course of action implemented to efficiently become and remain best of the best.

Benchmarking works well when the process being benchmarked is essentially the same at the multiple units (either internal or external) participating in the exercise. For example, considering Adamawa State University, Mubi as the organization of focus for this study, it's useful to compare the cost of running the same programme, admitting the same number of students or processing the same type of paycheck or benefit claim across multiple Nigerian Universities. But benchmarking is not informative when it is used to compare fundamentally different processes, activities or products. In the words of Kelessidis (2000), benchmarking entails gathering information from one organization to beneficially apply it to another organization. The scope is to improve the processes performed at the recipient organization by applying efficient work processes (work done by people, equipment and information systems). It is a valuable Business Engineering Technique and its application not only identifies innovative work processes but also involves discovering the thinking behind innovation.

Employee job satisfaction is essential to the success of any organization. A high rate of employee contentedness is directly related to a lower turnover rate. Thus, keeping employees' satisfied with their careers should be a major priority for every employer. While this is a well known fact in management practices, economic downturns like the current one seem to cause employers to ignore it (Gregory, 2008).

There are numerous reasons why employees can become discouraged with their jobs and resign, including high stress, lack of communication within the organization, lack of recognition, or limited opportunity for growth. Management should actively seek to improve these factors through benchmarking if they hope to lower their turnover rate. Even in an economic downturn, turnover is an expense best avoided (Gregory, 2008).

Despite its wide usage in scientific research, as well as in everyday life, there is still no general agreement regarding what job satisfaction is. In fact there is no final definition on what job represents (Aziri, 201 1). Therefore, before a definition on job satisfaction can be given, the nature and importance of work as a universal human activity must be considered (Aziri, 2011). Aziri (2011) defined job satisfaction as any combination of psychological, physiological and environmental circumstances that cause a person truthfully to say I am satisfied with my job. According to this approach although job satisfaction is under the influence of many external factors, it remains something internal that has to do with the way how the employee feels. That is, job satisfaction presents a .set of factors that cause a feeling of satisfaction.

According to Morse (1997) "Satisfaction refers to the level of fulfilment of one's needs, wants and desire. Satisfaction depends basically upon what an individual wants from the world, and what he gets." Employee satisfaction is a measure of how happy workers are with their job and working environment. It is sure that there may be many factors affecting the organizational effectiveness and one of them is the employee satisfaction (Sageer, Rafat and Agarwal, 2012). Effective organizations should have a culture that encourages the employee job satisfaction, (Bhatti and Qureshi, 2007). 
Employees are more loyal and productive when they are satisfied (Hunter and Tietyen, 1997), and these satisfied employees affect the employees performance and organizational productivity, (Potterfield, 1999). Therefore, if benchmarking is not limited to identifying best practices, but also consists in analyzing and deepening their own practices, those of the competition and also their application within the organization as given by Bouin and Simon (2001), then, in order to achieve and ensure adequate employees' job satisfaction in an organization, management of the organization need to set a benchmark which can create a conducive and harmonious atmosphere that can compete effectively with the competitors in the industry.

\section{Objectives of the Study}

The objective of this study was to assess if benchmarking has an effect on employees job satisfaction in Adamawa State University, Mubi.

\section{Hypothesis}

In line with the objective of this study, the following hypothesis was formulated:

Ho: There is no any significant effect of benchmarking on employees job satisfaction in Adamawa State University, Mubi.

\section{Statement of the Problem}

Benchmarking in the workplace is an oftenmisunderstood concept. Benchmarking is a term that many managers and organizations think they understand, but few actually do, and even fewer really put into practice. Benchmarking is a dynamic and evolutionary tool, it involves the process of identifying, analyzing and ado the practices of the best performing organizations, in order to improve performance in own organization. Benchmarking is a too) for learning about how to improve activity, processes and management. Benchmarking is an information system that allows an enterprise to display their development strategy.

Several studies done in the field of benchmarking in organization revealed that many of managers does not recognize about the real importance of benchmarking and its effect on employees job satisfaction. Also, despite some researches done on benchmarking in many organizations, none was able to looked at public organization and above all, an academic institution like Adamawa State University, Mubi. Finally, records snows that there has been a growing interest as to how to ensure or improve employees job satisfaction in an organization, but there is no any clear-cut consensus as to whether benchmarking plays a role in improving employees job satisfaction. Hence, this study was necessitated in order to examine if benchmarking has an effect on employees job satisfaction in Adamawa State University, Mubi.

\section{Methodology}

A descriptive research design with survey method was applied in this study. The study used both the primary and the secondary data for the purpose of this study. Secondary data were collected from available books, publications, research studies, articles and websites. The population of this study encompasses all the 759 staff of Adamawa State University, Mubi. A closedended questionnaire was designed to collect primary data. Taro Yamani's formula was used ascertain the sample population and the sample was chosen through simple random sampling technique. Taro Yamani's formula which is as follows:

Sample size $(\mathrm{n}) \frac{\mathrm{N}}{1+\mathrm{N}(\mathrm{e})^{2}}$

Where:

Where; $\mathrm{N}$ tifi Number of the population

$\mathrm{n}=$ sample size desired to be covered

$\mathrm{e}=$ error estimate/significance level, given as 0.05

$1=$ constant

Substituting for value

$(\mathrm{n})=\frac{759}{(0.052)}$

$1+759(0.052)$

$\underline{759}$

2.8975

$\mathrm{n}=262$

Therefore to compute a sample size " $n$ " which is a representative of all confidence limit or 0.05 significant levels by using Taro Yamani's formula is 262.

Therefore, after collecting all necessary data, data have been analyzed and tabulated descriptively. And, this tabulated information used to measure perceived job satisfaction and dissatisfaction level of the employees as a result of benchmarking. To measure the satisfaction level a 4 point scale has been used which is denoted by $1=\mathrm{D}, 2=\mathrm{U}, 3=\mathrm{A}$, and $4=\mathrm{SA}$ 


\section{Review of Related Literature}

Why Should Adamawa State University, Mubi use

\section{Benchmarking?}

Why should higher education organisations care about benchmarking? In a word: competition (Epper, 1999). In the past, it may have been possible to identify friendly rivals but recently the competitive landscape is changing quickly with new, non-traditional rivals that may be overlooked as competitors or benchmarking partners (Epper, 1999).

One of the most important benefits of benchmarking is the discovery of innovative approaches. Benchmarking highlights problem areas and the potential for improvement, providing an incentive to change, and assists in setting targets and formulating plans and strategies (Meade, 1998). Benchmarking provides assessments of quality that identify measures that give a valid and balanced, current picture of the parameters that distinguish courses, universities or sections of a university (McKinnon, et al., 2000).

As a result of good benchmarking, university leaders would know how their institution rates in certain areas in comparison with others, ascertain their competitive position relative to others, and also know how their institution can be improved (McKinnon, et al., 2000). Benchmarking may enable an institution to lay a legitimate claim to being "distinguished" in a particular area (Dunn, McCarthy, Baker, Halonen, \& Hill, 2007). The findings from benchmarking enable universities to prioritise resources and use their resources to best effect (McKinnon, et al., 2000). Benchmarking can ensure that plans are being carried out and demonstrate areas of merit to stakeholders (Wilson \& Pitman, 2000). Yet benchmarking distinguishes between real innovation and simple reputation as it focuses on demonstrating best practices beyond their initial launch (Epper, 1999).

To maximise the benefits of benchmarking, institutions must undergo a thorough self-analysis and have a clear understanding of their own processes (Epper, 1999) which may be more useful than the comparison with another organisation. Beyond the potentially humbling learning experience of benchmarking, the networking creates opportunities for further collaboration (Epper, 1999).

\section{Benchmarking - A New Path Towards Employees Job Satisfaction} Typologies Concerning Benchmarking
Managers of a company may choose one of the following types of benchmarking:

Internal benchmarking is done by the comparative analysis of processes between two compartments of the same organization (one of them being considered as reference). Regarding access to information, this is unlimited. The potential gains can only reach $10 \%$, a lower level than the external benchmarking. Experts believe that internal benchmarking should be considered an intermediate step in the process of reporting at the identified leader in the field.

External benchmarking targets organizations outside the company. If you cannot establish a partnership in practice of benchmarking, getting data in this case is done with great difficulty.

Competitive benchmarking consists in analyzing strategies, processes and practices of other competing organizations or of those with same activity. Data collection is performed with difficulty, fearing industrial espionage. Earnings can range up to $20 \%$;

Functional benchmarking aims comparison a certain functions of the organization performing benchmarking with a similar function of a particular organization taken as reference in order to identify new options for improving future work. The advantage of this type of benchmarking practice consists in easier way to collecting data, because non-competitive ratio that exists between companies showing interest in creating these partnerships that can generate positive results for all parties. Earnings may reach 35\%;

Generic Benchmarking is realized between enterprises from different sectors, related to the processes and working methods. Data exchange is done relatively easily, and the gain obtained by this method can be up to $35 \%$;

Benchmarking strategic (long-term) involves the analysis and evaluation of strategies that have generated high performances; implies the comparison of strategy, allowing the quantification of future development strategies of the company, regarding processes, technology and distribution;

Horizontal benchmarking - aimed at identifying best practices in operation processes of 
organizations that are recognized as market leaders, but who are not direct competitors of the organization that conducts benchmarking. The main advantage lies, in this case, in the ease with which data can be obtained, because organizations are not competing (Lonescu and Bigioi, 2004).

\section{Implementation and Deployment of Benchmarking Process}

Implementing a benchmarking process helps the management to obtain data to support decisionmaking, to formulate and implement the strategy, but also requires the full support from management (time, effort, financial resources). The purpose of the benchmarking process should be clearly defined at the outset: what you want to know, why, and what you intend to do with the results?

In the process of benchmarking must be taken decisions regarding the purpose and expected results and must be identified areas or aspects of the organization's activities which will be subject of benchmarking process. These must be consistent with the organization's profile and mission and organizational development. It is essential to have a clear understanding of the issues and, depending on needs, these must be prioritized so as to be launched a realistic benchmarking exercise, having adequate resources.

The reasons for making, in a company, a benchmarking with leading organizations are numerous. Benchrnarking can be applied in situations in which the organization:

$>$ is still competitive, but competition is becoming stronger and stronger and key indicators of the company are deteriorated;

$>$ is in difficulty and the management trying to reach a level of total quality (according to Iso 9000);

$>$ needs innovative ideas, other than those proposed by its collaborators;

$>$ is occasionally and sincerely interested how unfolds various processes in the highest rated companies on the market;

$>$ is in a survival situation.

In order for benchmarking to become an effective process to improve the functioning of a company, the following need to be pursued:

$>$ evaluating its own work, identifying strengths and weaknesses, which can be turned into opportunities for improvement; knowing the competitors and the leader in its

\section{Advantages of benchmarking}

The advantages are:

A. Minimizes the costs and saves time to adapt the best practices of other companies rather than reinvent them in-house.

B. Helps in implementation of upcoming changes and sophisticated technological improvements, arising out of change across industries.

C. Bridges the competitive gaps in one's own concern from other competing firms.

D. Initiates the formulation of strategic goals and objectives based on the external models for improving activities and processes in the organization.

E. Stimulates an organization to overcome its inertia and think differently in the context of the brandnew approaches/models implemented elsewhere.

F. Facilitates organizational learning and,

G. Drags improvement in critical areas within the organization by adapting best practices and processes (Sekhar, 2010).

\section{Key Drivers n Making Success of Benchmarking}

I. Identifying other companies which are role models for learning,

II. Acquiring reliable and valid data from these companies about their best practices and standards and how these are set in the critical areas of one's concern,

III. Determining current competitive gaps and understanding the strategic and tactical reasons for the gaps,

IV. Reengineering, improving, or innovating upon existing practices and processes to achieve better standards in critical areas,

V. Set up an action plan to induct the identified betterments,

VI. Motivating the employees for effective implementation of the process of benchmarking (Sekhar, 2010).

If the same set of people are involved in benchmarking and in implementing the identified changes, managing change does not run the risk of resistance. On the other hand, it may even inspire creativity and commitment to change. The abilities, experience, professional competence, influence and commitment of the people involved in benchmarking are the other factors critical to its success. A majority of employees can be tuned to benchmarking if its 
success can be exemplified with respect to a particular activity or process. The progress should be regularly monitored and the standards recalibrated to achieve continuous improvement (Harigopal, 2006; Chadha, 2007).

\section{Employee Job Satisfaction}

The study of job satisfaction is a topic of wide interest to both people who work in organizations and people who study them. Job satisfaction has been closely related with many organizational phenomena such as motivation, performance, leadership, attitude, conflict, moral etc. Researchers have attempted to identify the various components of job satisfaction, measure the relative importance of each component of job satisfaction and examine what effects these components have on employees' productivity.

Spector (1997) refers to job satisfaction in terms of how people feel about their jobs and different aspects of their jobs. Ellickson and Logsdon (2002) support this view by defining job satisfaction as the extent to which employees like their work. Schermerhorn (1993) defines job satisfaction as an affective or emotional response towards various aspects of an employee's work. Reilly (1991) defines $\cap$ job satisfaction as the feeling that a worker has about his job or a general attitude towards work or a job and it is influenced by the perception of one's job. Wanous and Lawler (1972) refers job satisfaction is the sum ofjob facet satisfaction across all facets of a job. Abraham Maslow(1954) suggested that human need a from a five-level hierarchy ranging from physiological needs, safety, belongingness and love, esteem to self-actualization. Based on Maslow's theory, job satisfaction has been approached by some researchers from the perspective of need fulfilment.

Job satisfaction and dissatisfaction not only depends on the nature of the job, it also depend on the expectation what's the job supply to an employee (Hussami, 2008). Lower convenience costs, higher organizational and social and intrinsic reward will increase job satisfaction (Willem et al., 2007). Job satisfaction is complex phenomenon with multi facets (Xie and Johns, 2000); it is influenced by the factors like salary, working environment, autonomy, communication, and organizational commitment (Lane, Esser, Holte and Anne, 2010; Vidal, Valle and Aragón, 2007).
Job satisfaction is an area that has been well researched in the industrial and organizational psychology literature. However, it is a concept that is still surrounded by controversy because much of the literature is inconclusive in nature (Mushipe, 2011).

Job satisfaction is a very important attribute which is frequently measured by organizations. Organizational scholars have long been interested in why some people reports being very satisfied with their jobs, while others express much lower levels of satisfaction. (Locke, 1976). The drive to understand and explain job satisfaction has been motivated by useful and practical reasons, as it could increase productivity, enhance organizational commitment, lower absenteeism and turnover, and ultimately, increase organizational effectiveness.

Lawler and Porter (1967) give their model of job satisfaction which unlike the previous model places a special importance on the impact of rewards on job satisfaction, Figure 1.

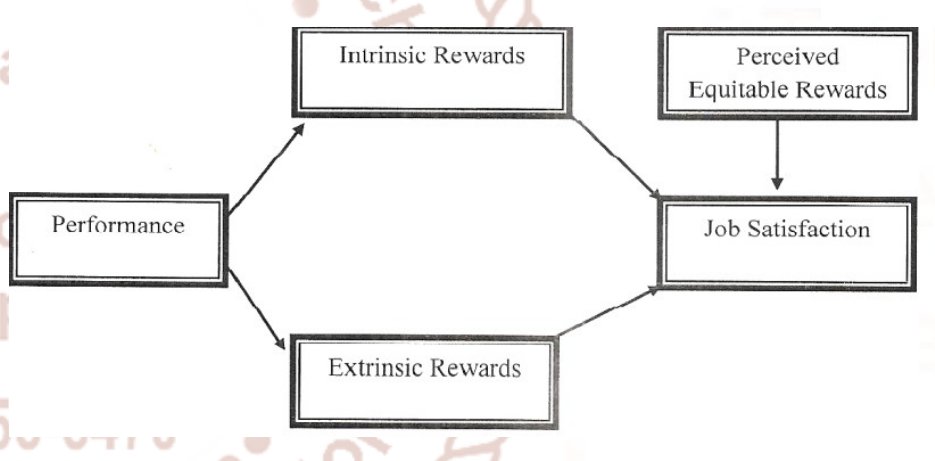

Figure 1: Lawler's and Porter's Model of Job Satisfaction (Lawler And Porter, 1967)

According to this model the intrinsic and extrinsic rewards are not directly connected with job satisfaction, because of the employees perceptions regarding the deserved level of pay.

\section{Discussions, Analysis and Findings}

From the 262 questionnaire administered to the respondents, only 250 were fully returned and retrieved by the researcher, and hence the presentation and analysis were done based on the fully returned questionnaire. 
International Journal of Trend in Scientific Research and Development (IJTSRD) ISSN: 2456-6470

Benchmarking Improves Employees Job Satisfaction

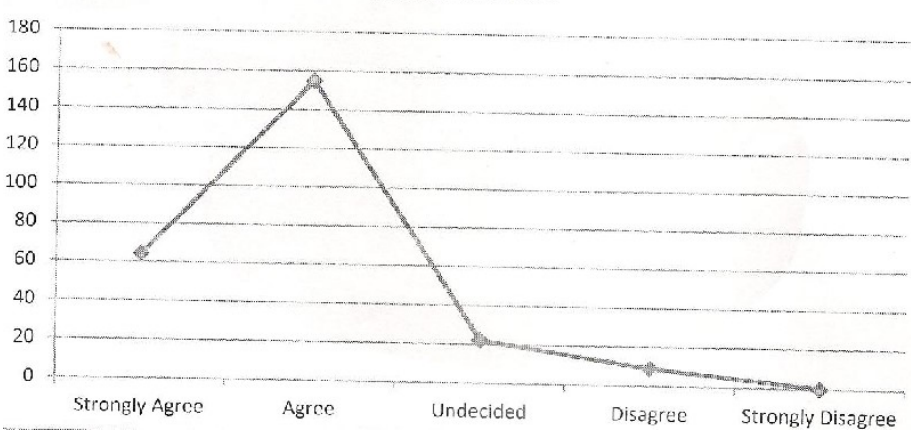

Figure 2: Benchmarking Improves Employees Job Satisfaction

It can be seen from the data presented above that 64 respondents out of the 250 sampled respondents strongly agreed that benchmarking improves employees' job satisfaction in Adamawa State university, Mubi. In the same vein, 155 respondents also agreed, while 22 respondents said that they don't know and only 9 respondents disagreed.

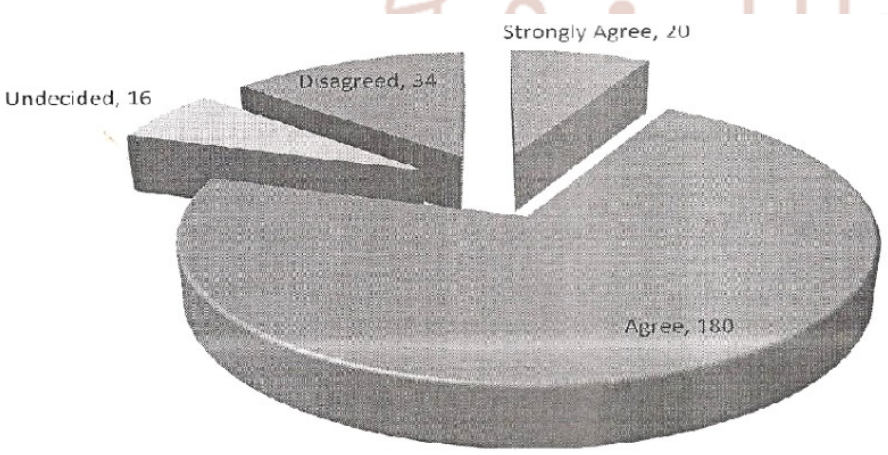

Figure 3: Benchmarking aid in the Standardization of the School

From figure 2 above, it is obvious that benchmarking aid in the standardization of Adamawa State University, Mubi because it makes the management to compare its activities with other universities such that adequate measures can be done in improving the standard of the school. This conclusion was derived from the responses above where 20 respondents strongly agreed with the conclusion, 180 respondents also are in agreement with the conclusion. On the contrary, 34 respondents disagreed while 16 respondents remain undecided.
Level of Satisfaction among Employees

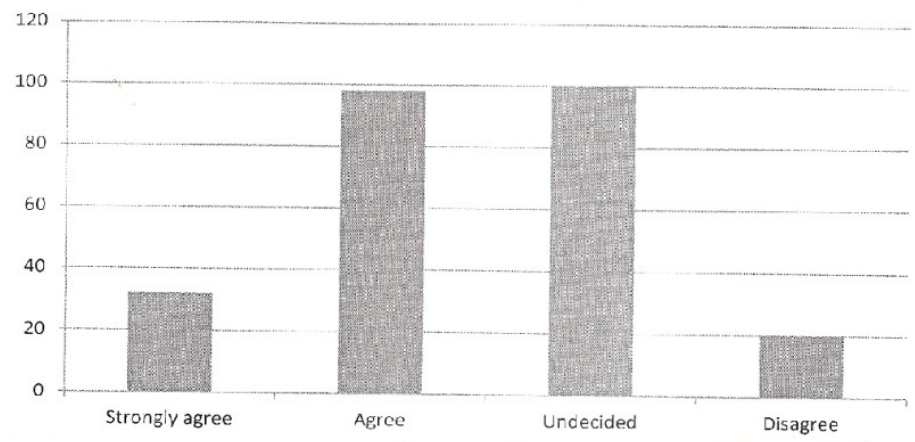

Figure 4: The Staff of Adamawa State University,

Mubi are not so uch satisfied with their job

In order to ascertain the level of satisfaction of among staff, 32 respondents strongly agreed and 98 respondents also agreed that the staffs of Adamawa State University, Mubi are not so much satisfied with their job. 100 respondents remain undecided, while 20 respondents disagreed.

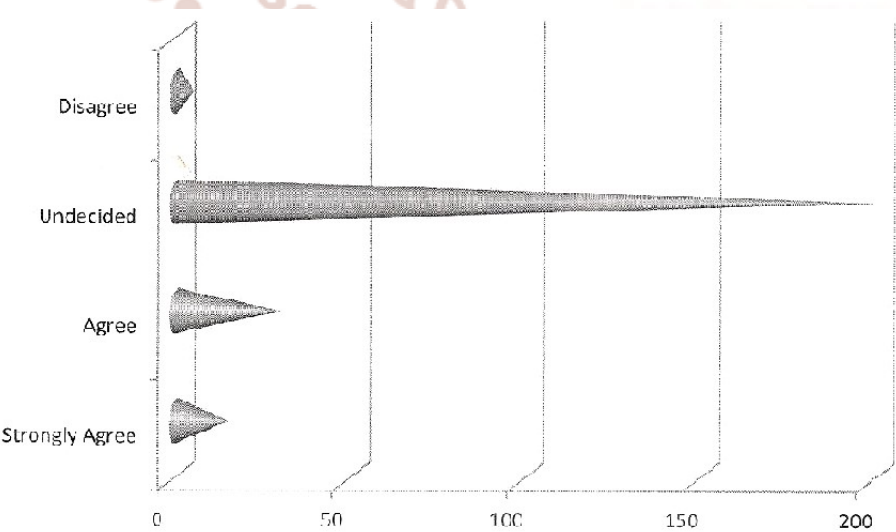

Figure 5: There are some challenges affecting benchmarking in Adamawa State University, Mubi

From the responses presented in figure 4 above, it is obvious that most of the staff don't know whether there are some challenges affecting benchmarking in Adamawa State University, Mubi.

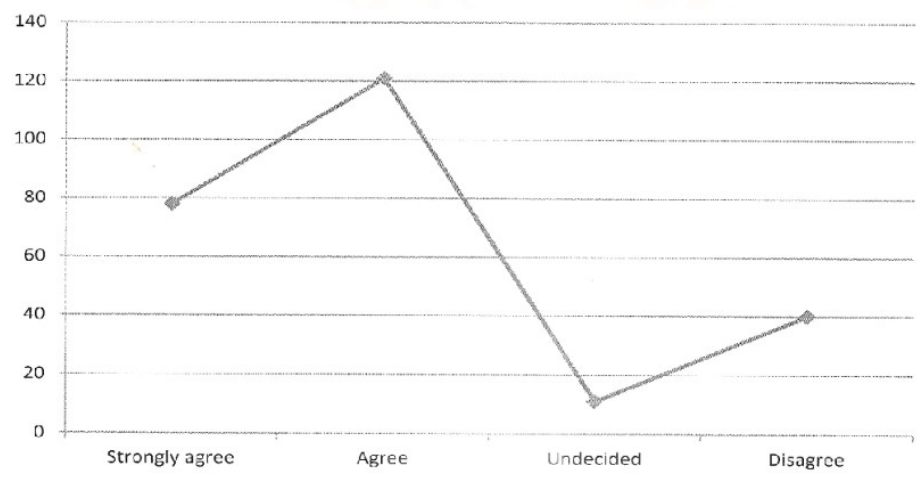

Figure 6: Effect of benchmarking on employees job satisfaction in Adamawa State University, Mubi 
From the responses presented in figure 5 above, 78 respondents strongly agreed that benchmarking has an effect of employees job satisfaction, 121 respondents also concurred with opinion above, while 11 respondents remain undecided and 40 respondents disagreed. This response help in validating the hypothesis which states that there is no any significant effect of benchmarking on employees job satisfaction in Adamawa State University, Mubi. From the majority of the respondents, the null hypothesis is reject and hence, there is a significant effect of benchmarking on employees' job satisfaction in Adamawa State University, Mubi.

\section{Conclusion and Recommendations}

Based on the analysis presented above, this study concludes that there is a significant effects of benchmarking on employees' job satisfaction in Adamawa State University, Mubi. It claims that the cultural dimension has to be taken into account whenever an organization wants to adopt practices such as benchmarking which are borrowed from alien societies. The results of this study have original implications for organization as well as academic researchers that employee satisfaction has positive significant correlations with benchmarking. The study however, recommend that future studies should be conducted such that it may analyze the reasons why benchmarking fail in order organization as well as identifying some other factors that may enhance employees job satisfaction.

\section{REFERENCES}

1. Ajelabi, I. and Tang, Y. (2010). The Adoption of Benchmarking Principles for Project Management Performance Improvement. International Journal of Managing Public Sector Information and Communication Technologies (IJMPICT) Vol. 1, No.2.

2. Aziri, B. (2011). Job satisfaction: a literature review Management research and practice vol. 3 issue 4.

3. Bhatti, K., \& Qureshi, T. (2007). Impact of employee participation on job satisfaction, employee commitment and employee productivity. International Review of Business Research Papers, 3(2), $54-68$.

4. Chadha, P. (2007). "Performance Management", MACMILLAN, New Delhi pp. 76- 77.
5. Cranny, C. J., Smith, P. C., \& Stone, E. F. (1992). Job satisfaction: How people feel about their jobs and how it affects their performance. New York: Lexington.

6. Dunn, L S., McCarthy, M. A., Baker, S., Halonen, J. S., \& Hill, G. W. (2007). Quality benchmarks in undergraduate psychology programs. American Psychologist, 62(7), 650-670. doi: 10.1037/0003066X.62.7.650

7. Ellickson. M \& Logsdon, K. (2002). Determinants of job satisfaction of municipal government employees [version]. Public Personnel Management, 3 1(3), 343-358.

8. Elnaga, A. A. \& Imran, A. (2014). The Impact of Employee Empowerment on Job Satisfaction: Theoretical Study. American Journal of Research Communication, Vol 2(1).

9. Epper, R. M. (1999). Applying benchmarking to higher education: Some lessons from experience. Change, 3 1(6), 24-31.

10. Gregory, K. (2008). The Importance of Employee Satisfaction. New York, N Y: Amacom.

11. Griffin M A, Patterson M G, West M A (2001). Job satisfaction and team work: the role of supervisor support. J. Organ. Behav., 22: 537550 .

12. Harigopal K (2006). "Management of Organizational Change”, Response books, New Delhi, pp. 182-186.

13. Hunter, W., \& Tietyen, D. (1997). Business to business marketing: Creating a common unity of customers. Lincolnwood-Illinois, McGraw-Hill Professional.

14. Hussami, M. (2008). A Study of nurses' job satisfaction: The relationship to organizational commitment, perceived organizational support, transactional leadership, transformational leadership, and level of education. Eur. J. Sci. Res., 22(2): 286-295.

15. Ionescu, A. M. and Bigioi, C. E. (2004). The Importance of Benchmarking In Making Management Decisions. http ://agpitt.ro/wp content/uploads/pdf/Modul\%20B enchmarking.pdf

16. Kaplan, R. S. (2005). The Limits of Benchmarking. Harvard Business School Publishing, 7(6). 
International Journal of Trend in Scientific Research and Development (IJTSRD) ISSN: 2456-6470

17. Kelessidis, V. (2000). Benchmarking. dissemination of innovation management and knowledge techniques. Unpublished Report produced for the EC funded project.

18. Lane KA, Esser J, Holte B, McCusker M. A. (2010). A study of nurse faculty job satisfaction in community colleges in Florida. Teach. Learn. Nurs., 5: 16-26.

19. McKinnon, K. R., Walker, S. H., \& Davis, D. (2000). Benchmarking: A manual for Australian universities. Canberra, Australia: Department of Education, Training and Youth Affairs, Higher Education Division.

20. Mushipe , Z. J. (2011). Employee Empowerment and Job Satisfaction: A Study of the Employees in the Food Manufacturing Sector in Zimbabwe. Interdisciplinary Journal of Contemporary Research In Business, Vol 3, No 8.

21. Potterfield, T. (1999). The business of employee empowerment: Democracy and ideology in the workplace. Westport, Conn, Greenwood Publishing Group.

22. Sageer, A., Rafat, S. and Agarwal, P. (2012). Identification of Variables Affecting Employee
Satisfaction and Their Impact on the Organization. Journal of Business and Management (IOSR-JBM Volume 5, Issue 1.

23. Sekhar, S. C. (2010). Benchmarking. African Journal of Business Management, Vol. 4(6), pp. 882-885.

24. Spector, P. E. (1997). Job satisfaction: Application, assessment, cause and consequences ,Thousand Oaks, CA, Sage Publications, Inc

25. Vidal M E S, Valle R S, Aragon BMI (2007). Antecedents of repatriates' job satisfaction and its influence on turnover intentions: Evidence from Spanish repatriated managers. J. Bus. Res., 60: 1272-1281.

26. Wilson, A., \& Pitman, L. (2000). Best practice handbook for Australian university libraries.

27. Wilson, A., Pitman, L., \& Trahn, I. (2000). Guidelines for the application of best practice in Australian university libraries: Intranational and international benchmarks. Canberra: Department of Education, Training and Youth Affairs, Higher Education Division, Evaluations and Investigations Programme. 